\title{
Targeting Neurogenesis with Mushroom Nutrition: A Mini Review
}

\author{
https://doi.org/10.54225/cjm.vol6.2010557
}

Dr. Elisabete Ferreiro, CNC-Center for Neuroscience and Cell Biology

CIBB-Centre for Innovative Biomedicine and Biotechnology, University of Coimbra, Coimbra, Portugal
Prof. Tito Fernandes, CIISA

Faculty of Veterinary Medicine, Lisbon University, Lisbon, Portugal

Neurogenesis is the process by which new neurons are formed in the brain. Neurogenesis is crucial when an embryo is developing, but also continues in certain brain regions after birth and throughout lifespan. The mature brain has many specialised areas of function, and neurons that differ in structure and connections. The hippocampus, for example, which is a brain region that plays an important role in memory and spatial navigation, alone has at least 122 different types of neurons ${ }^{[1]}$

Adult neurogenesis in the dentate gyrus of the hippocampus is highly regulated by several external conditions and cell-intrinsic factors to adapt to environmental changes.

Accumulating evidence suggests that adult-born neurons may play distinct physiological roles in hippocampus-dependent functions, such as memory encoding and mood regulation ${ }^{[2]}$.
Adult hippocampal neurogenesis is a process that describes the generation of new functional dentate granule cells (DGCs) from adult neural stem cells through the amplification of intermediate progenitors and neuroblasts, as well as the differentiation and integration of these new neurons into the existing neural circuits ${ }^{[3]}$.

\section{Diagram I}

Outline of the scheme of lineage progression and fate decisions during adult hippocampal neurogenesis.

A astrocyte;

GC granule cell;

NSC neural stem cell ${ }^{[4]}$.

\section{Diagram II}

As part of this process the newly generated granule cells then extend axons or dendritic branches to integrate themselves in the pre-existing network of cells that compose the hippocampal. Again, the integration relies on newly formed dendritic branches of pre-matured neurons that reach the dentate gyrus (DG) molecular layer (ML) from granule cell layer (GCL) and upon reaching the molecular layer (ML) layer these dendritic branches reach out to entorhinal cortex (EC) and lateral (LPP) and medial (MPP) path, forming novel synaptic connections ${ }^{[5]}$.

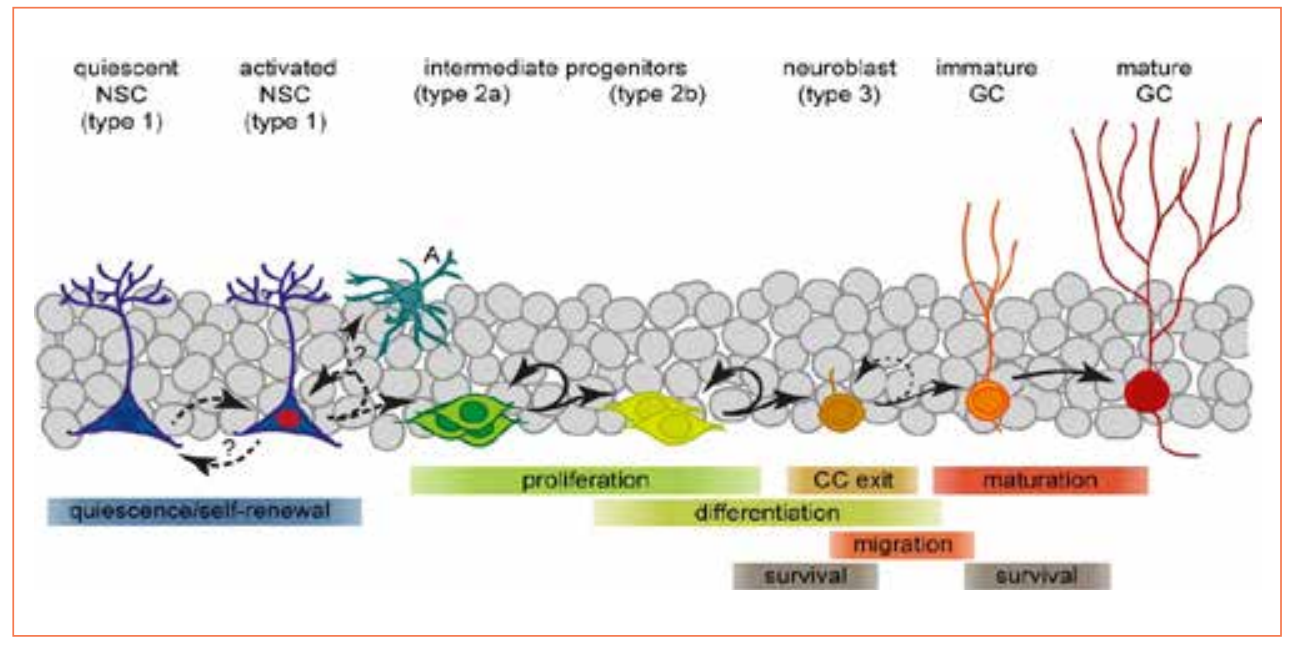

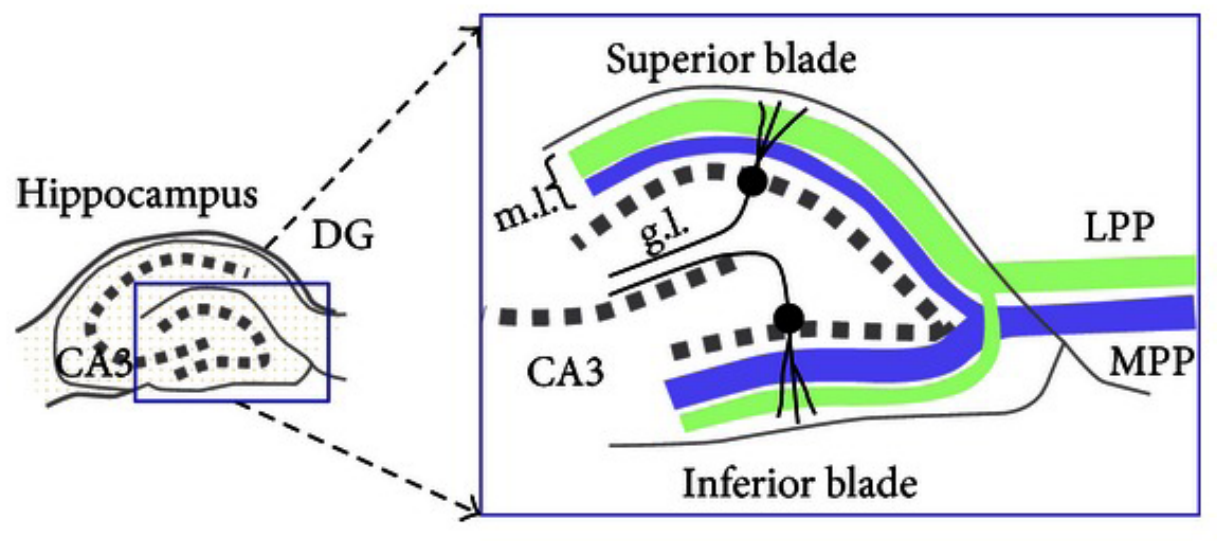


These cells can then project their axons to the Cornu Ammonis 3 (CA3), further establishing the hippocampal circuitry; hence maintaining or improving dendritic complexity is key to hippocampal function, a brain region important for spatial information, learning and memory functions.

When there is a malfunction in any of the processes, then a subsequent breakdown can be expected in either the quiescent pool (stem cell generator), loss of dendritic complexity (Diagram III), angiogenesis or neuroplasticity leading to a loss of memory.

Diagram III displays impaired morphology and activity in dentate gyrus granule cells in depression. In the healthy state, the granule cells have long thick apical dendrites ${ }^{[6]}$.

\section{Importance to Maintain Healthy Hippocampal Neurogenesis}

Brain cognitive reserve reflects the brains capacity to preserve normal functions, and has been used to explain the gap between tissue damage and clinical symptoms that has been observed in dementia and Alzheimer's disease $(A D)^{8}$. In early/moderate stages of Alzheimer's disease, cognitive reserve compensates neurodegeneration and allows the maintenance of patients' cognitive performance ${ }^{[7]}$. As outlined in Table I, there are several factors that modulate cognitive reserve:

\section{Diagram III}

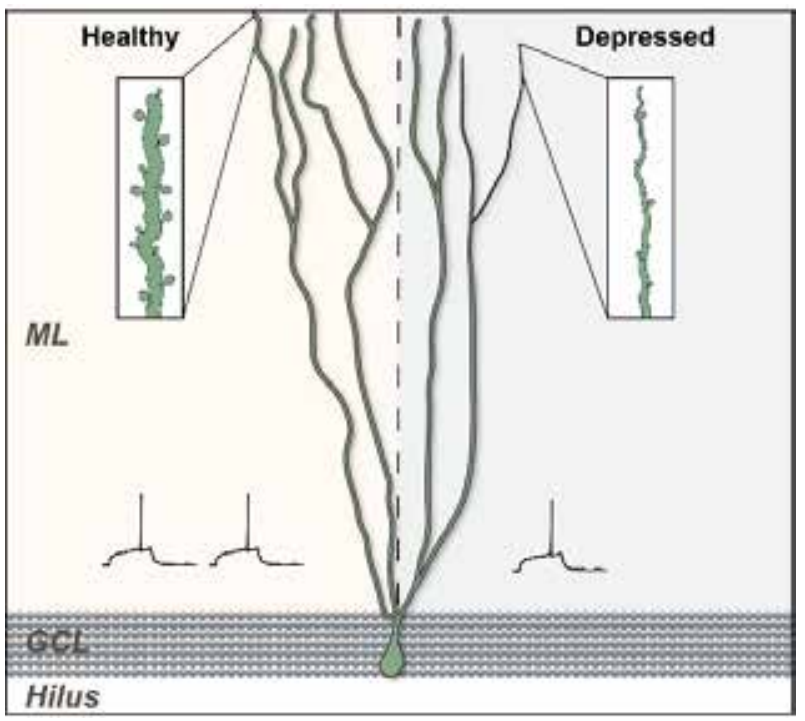

\section{Table I}

The impact of the aforementioned factors can translate into physical changes in brain morphology as outlined in Table $\|^{[9]}$.

\section{Table II}

Physical changes in brain morphology

\begin{tabular}{|l|l|}
\hline Beneficial Factors & Deleterious Factors \\
\hline Cognitive Exercises i.e. crossword, puzzles & Sedative Mental Activity i.e. excessive television viewing \\
\hline Education levels & Illiteracy \\
\hline Creative activities & Inadequate diet \\
\hline Diet & Solitude \\
\hline Regular Physical Exercise & Little Physical Exercise \\
\hline Social stimulus i.e. Bridge club & \\
\hline
\end{tabular}

\begin{tabular}{|l|l|}
\hline Improvement of cognitive reserve & Decline of cognitive reserve \\
\hline Increased brain size & Reduction in brain size \\
\hline Increase in the number of neurons & Reduction in the number of neurons \\
\hline Increased synaptic density & Reduction in synaptic density \\
\hline
\end{tabular}

Neurogenesis decreases with aging and declines may be linked to compromised cognitive-emotional resilience. Older individuals have less angiogenesis and neuroplasticity and a smaller quiescent progenitor pool.

In these AD patients there is a malfunction of the growth stages of hippocampal neurons or an unexplained severe deletion of these neurons or inability of these neurons to establish an integration within the existing circuitry of hippocampal function.

Due to the aforementioned malfunction and unexplained deletion of these neurons the continued pharmaceutical focus on the reduction of Tau and $\beta$-Amyloid proteins may be in need of review. Attempts to treat Alzheimer's disease with a "reduction" approach to Tau and $\beta$-Amyloid proteins has been disappointing ${ }^{[9]}$.

Until a pharmaceutical solution can be proven, could mushroom nutrition act as a disease modifying therapy by nutritionally targeting neurogenesis? How?

By focusing on:

1. Reduction of neuroinflammation by increasing Lipoxin A4. Lipoxin A4 (LXA4) is an endogenously produced eicosanoid that inhibits neutrophil recruitment and activation and blocks the generation of pro-inflammatory proteins. LXA4 acts as an endogenous "breaking signal" in the inflammatory process. Biomass 
forms of Coriolus versicolor and Hericium erinaceus increased Lipoxin $A 4$ and $A B$ uptake by phagocytic cells in rats which is recognized as a potential therapeutic target for $A D$ treatment ${ }^{[10][11]}$.

2. Combating viral infections that could be responsible for triggering dementia

Mushroom nutrition can be a source of natural bioactive compounds responsible for prevention and treatment of viral diseases through improvement of human immunomodulation. They boost antiviral cytokines or prevent the entry of the virus into the human cell that are responsible for triggering neurodegeneration [12][13][14][15].

\section{Rebalancing the microbiota in dementia diagnosed patients}

Food needs to cover the requirements of the human body and of the microbiota and ensure homeostasis. Mushrooms supply numerous enzymes, nucleosides, nucleotides and secondary metabolites essential for microbiota contributing to cell cycle regulation, apoptosis, autophagy, angiogenesis, metastasis, and signal transduction cascades ${ }^{[16]}$.

\section{Reducing oxidative and cellular stress response}

Mushroom nutrition reduces oxidative stress and free radicalinduced cell damage in neurodegenerative conditions ${ }^{[17]}$

\section{Maintaining hippocampal neurogenesis by supporting Wnt/ catenin signalling?}

The Wnt/B-catenin signalling pathway involves secreted glycoproteins acting through transduction pathways signalling cascade and ligands, controlling carcinogenesis, embryonic development, and tissue regeneration ${ }^{[18]}$.

They are dual function proteins, involved in regulation and coordination of cell-cell adhesion and gene transcription ${ }^{[19]}$, playing an important role in neurogenesis by enhancing the maturation of the newly generated dendritic network ${ }^{[20]}$. In fact, $\beta$-catenin is a protein with numerous functions in different cellular locations and its regulation is dependent of the action of several interplayers.

An important regulator of $\beta$-catenin is the glycogen synthase kinase-3 $\beta$ (GSK3 $\beta$ ) that promotes $\beta$-catenin degradation through its phosphorylation ${ }^{211}$. In pathological conditions in which GSK3 $\beta$ is highly activated, $\beta$-catenin is degraded, impairing the cellular processes dependent on its normal function. This degration is evident in $A D$ where both $W n t / \beta$-catenin signalling pathway and $\beta$-catenin levels were shown to be decreased in the brain of $A D$ patients ${ }^{[22]}$

Thus, $\beta$-catenin is a powerful therapeutic target, as its overexpression may function as a promoter of maturation and functional integration of immature neurons into the hippocampus. This possible therapeutic intervention may thus counterbalance scenarios where $\beta$-catenin is abnormally degraded and dysfunctional.

\section{Study Design}

In 2018, researchers at the Institute for Pharmacology and Experimental Therapeutics (IBILI), Faculty of Medicine at the University of Coimbra Portugal and in the Centre for Neuroscience and Cell Biology at the University of Coimbra led by Professors Frederico C. Pereira and A. Cristina Rego performed the following study on mice to evaluate the impact of mushroom nutrition on hippocampal neurogenic reserve ${ }^{[23]}$.

Using Coriolus versicolor (CV) biomass supplementation, the researchers took two groups of 2.5-month-old mice divided into one group taking $200 \mathrm{mg} / \mathrm{kg}$ every day for 2.5 months while the control group took saline. After 2.5 months the mice were sacrificed, and the following parameters were measured and compared between the two groups ${ }^{[23]}$.

While there was no change in the dentate gyrus volume or proliferation in newly generated neurons, it was found that mice treated with Coriolus versicolor biomass supplementation had a significant increase in the complexity of the long and short immature neurons (increase in dendritic complexity) ${ }^{[23]}$.

Table III: Summary of changes in the parameters

\begin{tabular}{|c|l|l|l|}
\hline $\mathbf{1}$ & Changes in volume of granular cell layer (GCL) and sub granular zone (SGZ) of the hippocampal dentate gyrus (DG) & None & None \\
\hline $\mathbf{2}$ & Changes in proliferation of DCX-positive cells & None \\
\hline $\mathbf{3}$ & Changes on number and nucleus area of immature neurons in the DG of mouse hippocampus & Yes & Yes \\
\hline $\mathbf{4}$ & Changes in differentiation features of DG short immature neurons of mouse hippocampus & Yes \\
\hline $\mathbf{5}$ & Changes in differentiation features of DG long immature neurons of mouse hippocampus & \\
\hline $\mathbf{6}$ & Changes in Wnt/ B-catenin signalling & \\
\hline
\end{tabular}




\section{Targeting Neurogenesis with Mushroom Nutrition:}

\section{A Mini Review}
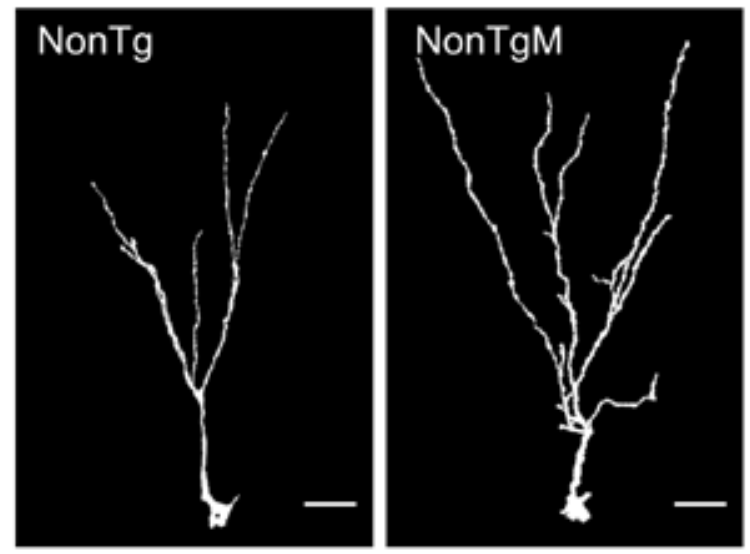

Image I

Of additional interest there was the fact that mice treated with Coriolus versicolor biomass had increased cytoplasmic and nuclear levels of $\beta$-catenin in immature neurons from hippocampal DG, suggesting that this protein may be a key molecule responsible for the increase in dendritic complicity in these cells.

\section{Conclusion}

The researchers demonstrated that supplementation with Coriolus versicolor biomass in mice promotes:

a) Increased dendritic arborization and complexity of newly generated neurons (short and long); and

b) Increase in the levels of $\beta$-catenin in the nucleus and cytoplasm of hippocampal newly generated neurons.

This indicates that Coriolus versicolor biomass promotes hippocampal neurogenic reserve in mice by increasing levels of $\beta$-catenin that may translate into enhanced cognitive reserve essential for learning and memory ${ }^{(24)}$.

Further clinical research is required to reconfirm these results.

The Coriolus versicolor biomass used in this study was supplied by Mycology Research Laboratories Ltd. (Luton, UK). (www.mycologyresearch.com).

\section{AUTHORS:}

\section{Dr. Elisabete Ferreiro}

CNC-Center for Neuroscience and Cell Biology, CIBB-Centre for Innovative Biomedicine and Biotechnology, University of Coimbra, Coimbra, Portugal. beferreiro@gmail.com

\section{Prof. Tito Fernandes}

CIISA, Faculty of Veterinary Medicine, Lisbon University, Portugal. profcattitofernandes@gmail.com

\section{References:}

1. Wheeler DW, White $C M$, Rees $C L$, Komendantov $A O$, Hamilton DJ, Ascoli GA. Hippocampome.org: a knowledge base of neuron types in the rodent hippocampus. Elife. 2015 Sep 24;4:e09960. doi: 10.7554/eLife.09960. PMID: 26402459; PMCID: PMC4629441.

2. Toda, T., Parylak, S.L., Linker, S.B. et al. The role of adult hippocampal neurogenesis in brain health and disease. Mol Psychiatry 24, 67-87 (2019). https://doi.org/10.1038/s41380-018-0036-2.

3. Boldrini M, Fulmore CA, Tartt AN, et al. Human Hippocampal Neurogenesis Persists throughout Aging. Cell Stem Cell. 2018;22(4):589-599 e5. doi:10.1016/j.stem.2018.03.015

4. Urbach A, Witte OW. (2019). Divide or Commit - Revisiting the Role of Cell Cycle Regulators in Adult Hippocampal Neurogenesis. Front. Cell Dev. Biol., 24 April 2019 | https://d.org/10.3389/fcell.2019.00055

5. Greene P, Howard MD, Bhattacharyya R, Fellous J-M. (2013). Hippocampal Anatomy Supports the Use of Context in Object Recognition: A

Computational Model. Computational Intelligence and Neuroscience. Volume 2013. January 2013. Article No.: 2pp. https://doi.org/10.1155/2013/294878.

6. Umschweif G, Greengard P, Sag Y. (2019).The dentate gyrus in depression. Eur J Neurosci. 2021;53:39-64. DOI: 10.1111/ejn.14640.

7. Carapelle E, Mundi C, Cassano T, Avolio C. (2020). Interaction between Cognitive Reserve and Biomarkers in Alzheimer Disease. International Journal of Molecular Sciences. 2020; 21(17):6279. https://doi.org/10.3390/ijms21176279.

8. Moreno-Jiménez EP, Flor-García M, Terreros-Roncal J, Rábano A, Cafini F, Pallas-Bazarra N, Ávila J, Llorens-Martín M. Adult hippocampal neurogenesis is abundant in neurologically healthy subjects and drops sharply in patients with Alzheimer's disease. Nat Med. 2019 Apr;25(4):554-560. doi: 10.1038/ s41591-019-0375-9. Epub 2019 Mar 25. PMID: 30911133.

9. After 190 Tries Are We Any Closer to a Cure For Alzheimer's? Bloomberg Businessweek June 27th -July 3rd, 2016. https://www.bloomberg.com/news/ articles/2016-06-27/after-190-tries-are-we-any-closer-to-a-cure-for-alzheimer-s

10. Trovato A, Siracusa R, Di Paola R, Scuto M,Fronte V, Koverech C, Luca M, Serra A, Toscano M.A., Petralia A, Cuzzocrea S, Calabrese V. (2016). Redox modulation of cellular stress response and lipoxin A4 expression by Coriolus versicolor in rat brain: Relevance to Alzheimer's disease pathogenesis. Neurotoxicology. 53:350-8. doi: 10.1016/j.neuro.2015.09.012. 2016.

11. Trovato A, Siracusa $R$, Di Paola R, Scuto $M$, Ontario ML, Bua $O$, Di Mauro $P$, Toscano MA, Petralia CC, Maiolino L, Serra A, Cuzzocrea S, Calabrese V. (2016) Redox modulation of cellular stress response and lipoxin A4 expression by Hericium erinaceus in rat brain: relevance to Alzheimer's disease pathogenesis. Immun Ageing. 13:23. doi: 10.1186/s12979-016-0078-8. Jul 9 2016.

12. Licastro, F.; Porcellini, E. Activation of Endogenous Retrovirus, Brain Infections and Environmental Insults in Neurodegeneration and Alzheimer's Disease. Int. J. Mol. Sci. 2021, 22, 7263. https://doi.org/10.3390/ijms22147263.

13. Ben Readhead, Jean-Vianney Haure-Mirande, Cory C. Funk, Matthew A. Ricards, Paul Shannon, Eric M. Reiman, Eric E. Schadt, Michelle E. Ehrilich, Sam Gandy and Joel T. Dudley. Multiscale Analysis of Independent Alzheimer's Cohorts Find Disruption of Molecular, Genetic, and Clinical Neworks by 
Human Herpesvirus Neuron 99,1-19 July 2018.

14. Monro JA. Chronic Fatigue Immune Dysfunction Syndrome. Journal of Integrative Medicine. 8:101-108. 2004.

15. Monro JA. Treatment of Cancer with Mushroom Products. Arch Env Health 58:533-537. 2003.

16. Aritson Cruz, Lígia Pimentel, Luis M. Rodríguez-Alcalá, Tito Fernandes, and Manuela Pintado, "Health Benefits of Edible Mushrooms Focused on Coriolus versicolor: A Review." Journal of Food and Nutrition Research, vol. 4, no. 12 (2016): 773-781. doi: 10.12691/jfnr-4-12-2.

17.Trovato A, Pennisi M, Crupi R, Di Paola R, Alario A, Modafferi S, Di Rosa G, Fernandes T, Signorile A, Maiolino L, Cuzzocrea S, Calabrese V. (2017). Neuroinflammation and mitochondrial dysfunction in the pathogenesis of Alzheimer's Disease: modulation by Coriolus versicolor (Yun-Zhi) nutritional mushroom.

J Neurol Neuromed 2017;2(1):19-28

18. Sethi JK, Vidal-Puig A. Wnt signalling and the control of cellular metabolism. Biochem J. 2010 Mar 15;427(1):1-17. doi: 10.1042/BJ20091866. PMID: 20226003; PMCID: PMC4301310.

19. Valenta $T$, Hausmann $G$, Basler $K$. The many faces and functions of $\boldsymbol{\beta}$-catenin. EMBO J. 2012 Jun 13;31(12):2714-36. doi: 10.1038/emboj.2012.150. Epub 2012 May 22. PMID: 22617422; PMCID: PMC3380220.

20. Yu X, Malenka RC. Beta-catenin is critical for dendritic morphogenesis. Nat Neurosci. 2003 Nov;6(11):1169-77. doi: 10.1038/nn1132. Epub 2003 Oct 5. PMID: 14528308

21. Hur EM, Zhou FQ. GSK3 signalling in neural development. Nat Rev Neurosci. 2010 Aug;11(8):539-51. doi: 10.1038/nrn2870. PMID: 20648061; PMCID: PMC3533361.

22. He P. and Shen Y. Interruption of $\beta$-Catenin Signaling Reduces neurogenesis in Alzheimer's Disease. Journal of neuroscience 20 May 2009 (20) 6545-6557; doi: 10.1523/JNEUROSCI.0421-.2009

23. Ferreiro E, Pita IR, Mota SI, Valer J, Ferreira NR, Fernandes $T$, Calabrese V, Fontes-Ribeiro CA, Pereira FC, Rego AC. (2018). Coriolus versicolor biomass increases dendritic arborization of newly-generated neurons in mouse hippocampal dentate gyrus. Oncotarget. 2018; 9(68):3292932942. doi:10.18632/oncotarget.25978. https://www.ncbi.nlm.nih.gov/ pubmed/30250640

24. Ferreiro EB (2019). Presentation at the 10th Congresso de Fitoterapia de SEFIT, Friday, November 8th, 2019, Faculty of Medicine University of Santiago de la Compostela, Santiago de la Compostela, Spain.
Clinical Journal of Mycology is published by Aneid Press, a division of Aneid Lda.

\section{Editorial Advisor}

Tito Fernandes DVM,MSc,PhD,DSc,Dr HC mult, Dip ECVCN profcattitofernandes@gmail.com

\section{Design \& Production}

Allan Parker <www.pureland.co.uk>

Publishing Director

William Ahern <ahernbill@hotmail.com>

ISSN 1646-6551 